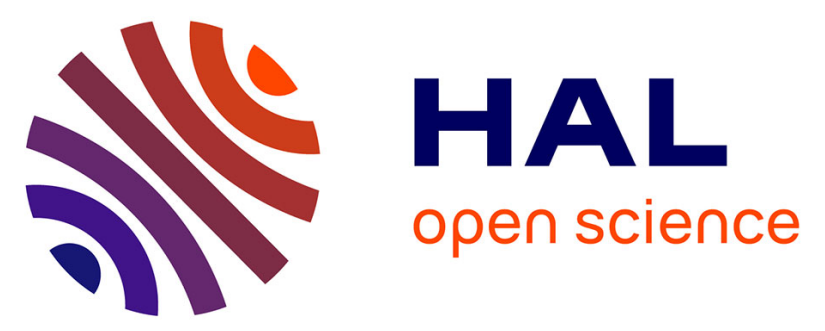

\title{
Why cyclic hygrothermal ageing modifies the transverse mechanical properties of a unidirectional epoxy-flax fibres composite?
}

Laetitia van Schoors, Thomas Cadu, Sandrine Moscardelli, Loïc Divet, Stéphane Fontaine, Olivier Sicot

\section{To cite this version:}

Laetitia van Schoors, Thomas Cadu, Sandrine Moscardelli, Loïc Divet, Stéphane Fontaine, et al.. Why cyclic hygrothermal ageing modifies the transverse mechanical properties of a unidirectional epoxy-flax fibres composite?. Industrial Crops and Products, 2021, 164, 26 p., graph., bibliogr. 10.1016/j.indcrop.2021.113341 . hal-03161203

\section{HAL Id: hal-03161203 \\ https://hal.science/hal-03161203}

Submitted on 5 Mar 2021

HAL is a multi-disciplinary open access archive for the deposit and dissemination of scientific research documents, whether they are published or not. The documents may come from teaching and research institutions in France or abroad, or from public or private research centers.
L'archive ouverte pluridisciplinaire HAL, est destinée au dépôt et à la diffusion de documents scientifiques de niveau recherche, publiés ou non, émanant des établissements d'enseignement et de recherche français ou étrangers, des laboratoires publics ou privés. 
Why cyclic hygrothermal ageing modifies the transverse mechanical properties of a unidirectional epoxyflax fibres composite?

Laetitia Van Schoors $^{\mathrm{a}^{*}}$, Thomas Cadu ${ }^{\mathrm{a}, \mathrm{b}}$, Sandrine Moscardelli ${ }^{\mathrm{a}}$, Loïc Divet ${ }^{\mathrm{a}}$, Stéphane Fontaine ${ }^{\mathrm{b}, \mathrm{c}}$, Olivier Sicot ${ }^{\mathrm{b}}$

aUniv. Gustave Eiffel, MAST-CPDM, F-77454 Marne-la-Vallée, France

'DRIVE EA1859, Univ. Bourgogne Franche-Comté, F-58000 Nevers, France

${ }^{c}$ Ecole Nationale Supérieure des Arts et Métiers ParisTech, 57070, Metz

*Corresponding author: Laetitia Van Schoors; e-mail address: laetitia.van-schoors@univ-eiffel.fr

Full postal address:

Université Gustave Eiffel

Campus de Marne-la-Vallée, Bâtiement Bienvenüe

5 Boulevard Descartes, Champs-sur-Marne

F-77454 Marne-la-Vallée Cedex 2

FRANCE

Abstract

The development of composites based on plant fibres has considerably grown in last decades; however, their high sensitivity to moisture limits their use in structural applications. The objective of this study is to determine and understand the impact of moisture variations during one-year cyclic hygrothermal ageing i.e. 52 cycles on the transverse properties of a unidirectional epoxy flax composite. A cycle consists of 3.5 days at $90 \%$ RH followed by 3.5 days at $40 \% \mathrm{RH}$. Compared to the studies usually carried out to determine the impact of ageing on the longitudinal properties of unidirectional composites, the determination of the transverse mechanical properties during this type of ageing allowed to focus on the contribution of the matrix and the interface on the evolution of the composite properties. The multi-scale analyzes provided identification of the phases responsible for the evolution of transverse mechanical properties induced by ageing. The transverse ultimate tensile strength drops by about $20 \%$ after the first week of ageing and slightly decreases up to 2 months. This evolution seems to be induced by the creation of flaws, in particular the phenomena of fibre-fibre and matrix-fibre debonding and the creation of cracks in the fibres initiated at the lumen level, revealed by SEM. The transverse modulus also strongly drops after 
the first week by about $18 \%$ to reach about $45 \%$ loss after one year of ageing. These evolutions are mainly linked to the physical plasticization of the epoxy matrix demonstrated by the reversible change of its glass transition temperature, but analyses showed that water does not lead to chemical degradation of the matrix.

Keywords:

- Flax fibre

- Composite

- Ageing

- Physico-chemical

- Transverse properties

\section{Introduction}

For many years, government directives have aimed at limiting the use of fossil resources in favour of materials that have less impact on the environment (Le Duigou and Baley, 2014). In the field of composites, one of the alternatives is the use of vegetable fibres such as flax, hemp, sisal, miscanthus... The flax fibres widely used as reinforcement fibres in thermosetting matrix have interesting properties, such as their lightness and their specific mechanical properties making them able to compete with glass fibres (Amiri et al., 2017; Baley, 2002; Berges et al., 2016; Cadu et al., 2018; Jeyapragash et al., 2020; Poilâne et al., 2014). However, these fibres also have the specificity of being hydrophilic, of having limited thermal stability and of being made up of photosensitive compounds such as lignin (Azwa et al., 2013). To increase the development and use of these composites, a better understanding of the ageing mechanisms of these materials is necessary.

Today the vast majority of studies on the ageing of composites reinforced with flax fibres have been carried out by immersing these materials in water (Assarar et al., 2011; Dhakal et al., 2007; A Le Duigou et al., 2014; Le Duigou et al., 2015; Li and Xue, 2016; Yan and Chouw, 2015). This kind of ageing can lead to a huge drop of mechanical properties i.e. ultimate tensile strength and modulus especially caused by irreversible degradations of the composite. These damages mainly come from the differences in hydrophilicity, at the micro-scale, between the different flax constituents and, at the macro-scale, between the flax fibres and the epoxy matrix. This ageing can also lead to a decrease in modulus only, without variation in tensile strength explained mainly by a reorientation of the microfibrils and a plasticization of the inter-fibre bonds (Sodoke et al., 2016).

The hydrophilicity differences generate a differential swelling responsible of internal stresses inside cell-wall layers (Baley et al., 2012; Le Duigou et al., 2015; Roudier, 2012) and at the fibre-matrix interface (Chilali et al., 
2018). In addition, and as mentioned in the literature, this swelling can lead to the formation of micro-cracks in the fibre initiated in the lumen area (Le Duigou et al., 2015) and within the matrix (Azwa et al., 2013; Li and Xue, 2016) that facilitate the diffusion of water into the composite. Water can also cause the dissolution of some fibre constituents such as pectin and hemicellulose, thereby accentuating the degradation of the interface (Li and Xue, 2016). These degradation mechanisms are further accentuated by immersion/drying cycles, due to an increase in the diffusion kinetics of water at the fibre-matrix interface with the number of cycles (Kim and Seo, 2006; Newman, 2009). However, despite the phenomena of swelling and hydrolysis of pectin and hemicellulose, Sodoke et al. (Sodoke et al., 2019) have demonstrated a good preservation of tensile strength and modulus even after 7 ageing cycles of an epoxy / cyaniethylated flax fibre composite, linked to the fact that the humidification drying cycle would promote recrystallization of the cellulose chains. Thus, the drop in mechanical properties linked to the swelling and hydrolysis of the fibres would be counterbalanced by the increase in the crystallinity index of flax fibres. The immersion / drying cycles can have also favored the phenomenon of hornification which causes a modification of the microstructure of the fibres, the formation of new hydrogen bonds in the fibre wall structure resulting in an increase of fibres strength and modulus (Mendes et al., 2019).

However, according to the chosen application, these materials can be subjected to environmental variations of humidity and will not be in contact with liquid water. Few studies deal with the hygrothermal ageing of epoxyflax composites.

Berges et al. and Scida et al. (Berges et al., 2016; Scida et al., 2013) have studied the impact of an ageing at constant humidity, with cycles between 85 and $90 \%$ RH, on the mechanical properties of epoxy/flax composite. They showed a strong decrease in modulus (> 50\% after 38 days at $40^{\circ} \mathrm{C}$ ). The ultimate tensile strength seems to be not or much less impacted $\left(0\right.$ and $12 \%$ after 38 days at $\left.40^{\circ} \mathrm{C}\right)$. These changes in mechanical properties have been attributed to physical plasticization phenomena of the fibres and the resin.

More recently, Cadu et al. (Cadu et al., 2019) and Koolen et al. (Koolen et al., 2020) have carried out hygrothermal ageing cycles in order to stimulate the differential swelling inside the epoxy/flax composite. These ageing cycles seem to lead to less dramatic damage evolution. After 52 cycles (one cycle is composed of a 3.5 days step at $90 \%$ RH followed by a 3.5 days step at $50 \% \mathrm{RH}$ ) of ageing at $55^{\circ} \mathrm{C}$, i.e. one year, Cadu et al. (Cadu et al., 2019) have determined a slight decrease in longitudinal mechanical performance of a unidirectional composite. The modulus and ultimate tensile strength respectively drop by $12 \%$ and about $13 \%$. These little evolutions are mainly attributed to fibre-fibre, and fibre-matrix debonding phenomena. Koolen et al. (Koolen et al., 2020) were interested in the evolution of the three-point bending properties of unidirectional epoxy/flax composite subjected to an ageing at 
$80^{\circ} \mathrm{C}$ with humidity cycles at $78 \% \mathrm{RH}$ and drying cycles at $25 \% \mathrm{RH}$. After 6 ageing cycles, the transverse tensile strength decreases from $28 \mathrm{MPa}$ to $25 \mathrm{MPa}$. As in the previous study, performance losses are explained by a fibrematrix debonding phenomenon and failure of the internal interfaces of the fibres bundles. Note that these authors emphasize the fact that the degradation is much less dramatic than the ageing in water and may be more representative depending on the intended application.

To determine the interface and matrix qualities of the unidirectional composites, transverse tensile properties are one of the commonly used methods. Thus, this paper aims at determining the influence of a long (up to one year) hygrothermal ageing consisting of cycles on the transverse mechanical properties of an epoxy/flax composite in order to better assess the effects of this ageing on the interface and the matrix. Then, based on a multi-scale analysis, we try to identify the phases (i.e. interface, fibres and matrix) responsible of the changes in mechanical properties observed during ageing cycles and to improve understanding of these ageing mechanisms of this type of composites.

\section{Materials and methods}

\subsection{Materials}

The matrix is a DGEBA epoxy resin (SR 8500) reticulated by an amine hardener (SZ 8525) produced by Sicomin@. The flax fibres (Linum usitatissimum) are pure unidirectional reinforcements FlaxTape ${ }^{\mathrm{TM}} 110$ produced by Lineo@. The area weight and density respectively are $96 \mathrm{~g} \cdot \mathrm{m}^{-2}$ and 1.45 (Cadu et al., 2018).

12-plies unidirectional composite has been manufactured by thermocompression, using optimized parameters (Cadu et al., 2018). A first curing step was carried out at $80^{\circ} \mathrm{C}$, for 1 hour under a pressure of 3 bars, followed by a cooling at $1^{\circ} \mathrm{C}$ per minute to $20^{\circ} \mathrm{C}$. Then a post-curing was performed at $80^{\circ} \mathrm{C}$ for 2 hours without pressure. This composite (figure 1) contains approximately $47 \%$ by volume of fibres and $2.5 \%$ of voids. Unidirectional tensile specimens conforming to geometry 4 of ISO 527, having dimensions of $250 \pm 0.5 \mathrm{~mm}$ long, $25 \pm 0.5 \mathrm{~mm}$ wide and $1.8 \pm 0.1 \mathrm{~mm}$ thick, were prepared. The edges of the composite samples were coated prior to the postcuring step with the same resin used for the fabrication.

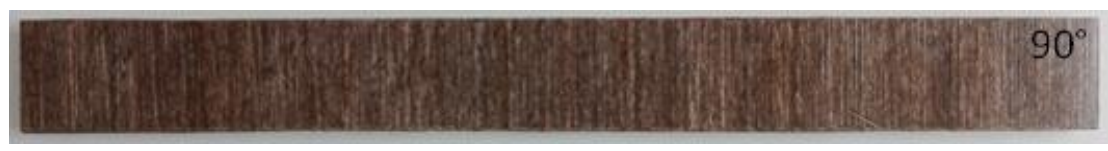

Figure 1: Photo of a unidirectional composite specimen at $90^{\circ}$ 


\subsection{Ageing Method}

The ageing method consists of performing humidification/drying cycles in a climatic chamber (CTS® C-20/200) to simulate the phenomena of differential swelling linked to the differences in hydrophilicity within the fibres and between the fibres and the matrix. Each cycle lasts one week and consists of a 3.5 days humidification phase at 90 $\pm 1 \% \mathrm{RH}$ and a 3.5 days drying phase at $40 \pm 1 \% \mathrm{RH}$. This ageing was carried out at $55^{\circ} \mathrm{C}$ to accelerate the kinetics of water diffusion but without generating melting of the waxes $\left(60^{\circ} \mathrm{C}\right)$ on the surface of the fibres while limiting the optimal development of microorganisms which is around $30^{\circ} \mathrm{C}$ (Gradeci et al., 2017). Ageing durations are 1 week, 1 month, 2 months, 6 months and 1 year for the composite, and 1 week, 1 month, 2 months, 6 months for the epoxy matrix without fibres.

Aged samples are taken from the climatic chamber after the $40 \% \mathrm{RH}$ phase. Before each characterization, all samples were conditioned at $23 \pm 1^{\circ} \mathrm{C}$ and $50 \pm 1 \% \mathrm{RH}$ for 7 days in a climatic chamber (CTS® $\left.\mathrm{CP}+10 / 600\right)$. This conditioning was carried out in order to get all the materials in the same water state (Cadu et al., 2018).

\subsection{Characterization Methods}

Fourier transform infrared spectroscopy (FTIR) was used to monitor the chemical evolution of the resin and composite surface $(\approx 10 \mu \mathrm{m})$ during ageing cycles. Analyses were performed on a Nicolet $\mathrm{TM}$ impact 380 spectrometer in attenuated total reflectance (ATR) mode, using a Durascope diamond. For each measurement, 32 scans were realized, with a resolution of $4 \mathrm{~cm}^{-1}$ over a wavelength range of 400 to $4000 \mathrm{~cm}^{-1}$. The spectra were normalized relatively to the peak present at $1508 \mathrm{~cm}^{-1}$, which corresponds to the aromatic groups $(\mathrm{C}=\mathrm{C})$ that do not normally evolve under the ageing conditions described in section 2.2 (El Yagoubi et al., 2014). For each ageing period, 5 measurements were carried out.

Modulated Differential Scanning Calorimetry has been used to determine the glass transition temperatures ( $\mathrm{Tg}$ ) of the matrix, $\mathrm{Tg}$ measurements were performed on reversible signals and crosslinking enthalpies on non-reversible signals. For the composite specimens, the crosslinking enthalpy measurements were also corrected by the mass of resin present in the composite sample. These analyses were carried out using a TA Instrument DSC 250 differential scanning calorimeter. The temperature profile used is a ramp from 25 to $200^{\circ} \mathrm{C}$ at a rate of $1{ }^{\circ} \mathrm{C} / \mathrm{min}$ and a modulation of $\pm 0.16^{\circ} \mathrm{C}$ during 60 seconds. Furthermore, the total enthalpy of reaction $\left(\Delta \mathrm{H}_{\mathrm{T}}\right)$ was measured on the non-crosslinked resin using a ramp from $-70^{\circ} \mathrm{C}$ to $280^{\circ} \mathrm{C}$ at a rate of $10^{\circ} \mathrm{C} / \mathrm{min}$. For each deadline, at least two tests 
were carried out for the composite and the resin. The masses of the composite samples are approximately of $30 \mathrm{mg}$ and those of the resin of $20 \mathrm{mg}$.

Dynamic Vapor Sorption (DVS) analyses were performed using a DVS-Advantage SMS. The DVS measurements achieve very accurate measures of the changes in mass of a sample based on the relative humidity of the environment. The DVS analyses are composed of a wet phase (3.5 days at $90 \% \mathrm{RH})$ and a dry phase (3.5 days at $40 \% \mathrm{RH}$ ) under similar humidity conditions to those of an ageing cycle. The samples used are in the form of small balls of about $0.5 \mathrm{~cm}^{3}$ for the fibres and squares of about $1 \mathrm{~cm}$ side for the composite and the resin.

Secondary Electron (SE) mode scanning electron microscopy (SEM) was used to assess the morphological changes associated with ageing. The composite samples were coated in an epoxy resin (EpoFix @) and were then polished to a mirror finish using the Struers $@$ LaboForce-100 polisher. To limit the effect of lubricant on the swelling of the fibres, the polishing was not carried out with water but with ethanol. Then they were covered with a thin layer of carbon to avoid sample loading during observations.

The mechanical properties were determined by monotonic tensile tests.

The tensile tests were performed on fibre bundles at room temperature on an Instron 5969 tensile machine equipped with a $2 \mathrm{kN}$ force transducer at a speed of $1 \mathrm{~mm} / \mathrm{min}$. The specimens analysed were conditioned and aged, then cut into strips with the following dimensional characteristics: width of $5 \pm 0.5 \mathrm{~mm}$, length between tabs of $150 \pm 0.5$ $\mathrm{mm}$, thickness of $0.2 \mu \mathrm{m}$. Steel tabs were glued using Loctite ${ }^{\circledR}$ to realize tensile tests. As the dispersion of the measurements can be important due to the variability of the intrinsic characteristics of the fibres, 40 specimens have been tested for each deadline.

The tensile tests on dumbbell-shaped type 5A epoxy resin specimens (ISO527-2, 2012) were also carried out at room temperature on a Shimadzu AGS-X tensile machine equipped with a $10 \mathrm{kN}$ force sensor and an integrated video extensometer system. They were performed at a speed of $1 \mathrm{~mm} / \mathrm{min}$. For each ageing period, 10 specimens were tested.

The tensile tests on the unidirectional composite material were carried out at room temperature on a MTS $100 \mathrm{kN}$ Criterion C45 tensile machine, equipped with a $10 \mathrm{kN}$ force transducer (precision $1 / 500^{\text {th }}$ or $\pm 0,02 \mathrm{kN}$ ) and a MTS 634.31F-24 mechanical extensometer, with a 50mm gauge length. The tests were carried out at a speed of 1 $\mathrm{mm} / \mathrm{min}$. For each ageing period, 5 composite specimens were tested. 


\section{Results and discussion}

Chemical, physicochemical, morphological and mechanical analyses have been realized to determine the mechanisms taking place in the composite throughout ageing. Firstly, the evolution of mechanical properties will be presented.

\subsection{Mechanical properties of the composite}

The initial mechanical properties of the composite, in the transversal direction $\left(90^{\circ}\right)$, were determined by tensile tests on non-aged samples. The properties measured are as follows: $\sigma_{\max }=20.4 \pm 1.2 \mathrm{MPa}$ and $\mathrm{E}=4.1 \pm 0.2 \mathrm{GPa}$. Then, the monotonous tensile tests carried out on the aged specimens enabled to follow the evolution of these properties during the ageing cycles (Figure 2).

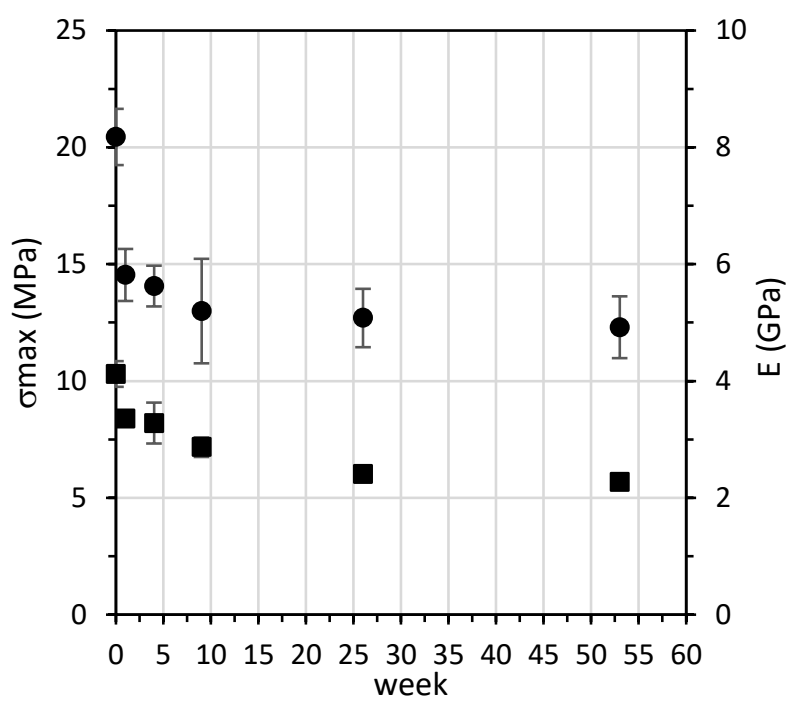

Figure 2: Evolution of the transverse mechanical properties of the composite (fibres oriented at $90^{\circ}$ ) as a function of the ageing time $(\bullet)$ Ultimate tensile strength and (घ) Young modulus. (Error bars indicate standard deviation).

It appears that the ultimate tensile strength $\left(\sigma_{\max }\right)$ (Figure 2$)$ drops by $22 \%$ after the $1^{\text {st }}$ week of ageing and then decreases more slightly until the $9^{\text {th }}$ week $(8 \%)$. Between 9 and 52 weeks, $\sigma_{\max }$ seems to stabilize. Indeed, the decreases in $\sigma_{\max }$ are less than $5 \%$ between these two ageing periods.

The Young modulus (E) (Figure 2) of the composite also decreases sharply after the $1^{\text {st }}$ week (-18\%). The reduction in modulus continues until the $26^{\text {th }}$ week $(23 \%)$ and almost seems to stabilize between the $26^{\text {th }}$ and $52^{\text {nd }}$ week $(3 \%)$. Therefore, the mechanical tests showed an evolution of the ultimate tensile strength and transverse Young modulus of the composite during the hygrothermal ageing cycles. Using a multi-scale analysis, we will first seek to 
understand whether the evolution of the ultimate tensile strength is related to the creation of defects in the different phases of the composite. Regarding the modulus, we will then try to identify whether the observed decrease is also related to the evolution of the resin, interfaces and/or fibres.

To identify the changes that take place within the composite during hygrothermal ageing cycles, several types of physicochemical analyses were carried out on composite and resin samples; the results are presented in the following sections.

\subsection{Effect of cyclic hygrothermal ageing on the resin}

In order to determine if the decreases of the mechanical properties of the composite are due to the degradation of the resin, analyses of Differential Scanning Calorimetry in modulated mode (mDSC) were carried out at each ageing period on composite and epoxy resin samples. The use of modulated mode makes it possible to dissociate the irreversible signal from the reversible signal. First, the irreversible signal was analysed to measure the residual crosslinking enthalpy $(\Delta \mathrm{Hr})$ of the epoxy resin without fibres and composite (Figure 3$)$. For the composite samples, $\Delta \mathrm{Hr}$ is recalculated based on the resin mass content in the sample. The analyses carried out on the non-crosslinked resin also made it possible to measure the total enthalpy of reaction $\Delta \mathrm{H}_{\mathrm{T}}=444 \mathrm{~J} / \mathrm{g}$; this value is consistent with the values found in the literature for epoxy resins DGEBA/amine for which $\Delta \mathrm{HT}$ is between 400 and $500 \mathrm{~J} / \mathrm{g}$ (Corsetti et al., 2013; Prime, 1973).

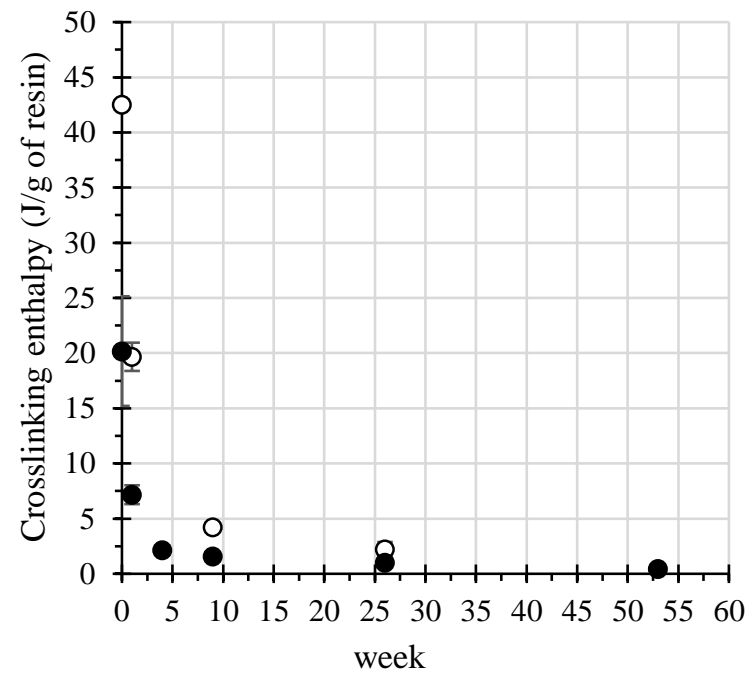

Figure 3: Evolution of the enthalpy measured on the non-reversible signal of the mDSC measurements: composite $(\bullet)$ and resin without fibres $(\circ)$, depending on the ageing time (Error bars indicate standard deviation). 
Figure 3 shows that the residual crosslinking enthalpy $(\Delta \mathrm{Hr})$ of the composite sharply decreases during the first 4 ageing weeks. Indeed, it decreases by $65 \%$ after the first week and by $25 \%$ between the first and the fourth week. During this period, $\Delta \mathrm{Hr}$ varies from $20.2 \pm 4.9 \mathrm{~J} / \mathrm{g}$ to $8.3 \pm 0.9 \mathrm{~J} / \mathrm{g}$, then to $2.8 \pm 0.1 \mathrm{~J} / \mathrm{g}$. After the $4^{\text {th }}$ week, $\Delta \mathrm{Hr}$ evolves very slightly, less than $3 \%$ between each tested deadline, reaching $0.47 \pm 0.03 \mathrm{~J} / \mathrm{g}$ after 52 weeks of ageing. Similarly, Figure 3 shows the evolution of $\Delta \mathrm{Hr}$ for the resin without fibres during ageing. As for the composite, this parameter decreases sharply during the cycles.

Thanks to these enthalpy measurements, the state of crosslinking of the resins can be evaluated and the degrees of progress of the resin crosslinking reaction $(\alpha)$ of the composite and of the epoxy resin without fibres were calculated based on the following relationship:

$\alpha=\frac{\Delta \mathrm{H}_{\mathrm{T}}-\Delta \mathrm{H}_{\mathrm{r}}}{\Delta \mathrm{H}_{\mathrm{T}}}$

With: $\alpha$ the progress rate of the crosslinking reaction; $\Delta \mathrm{H}_{\mathrm{T}}$ the total enthalpy of the reaction and $\Delta \mathrm{Hr}$ the enthalpy of residual crosslinking.

Figure 4 shows the progress of the resin crosslinking reaction in the composite and in the epoxy resin without fibres. It appears that, for non-aged materials, the crosslinking of the matrix is not complete but high, either for the composite or for the resin without fibres. In addition, the epoxy network tends to be completely crosslinked during ageing.

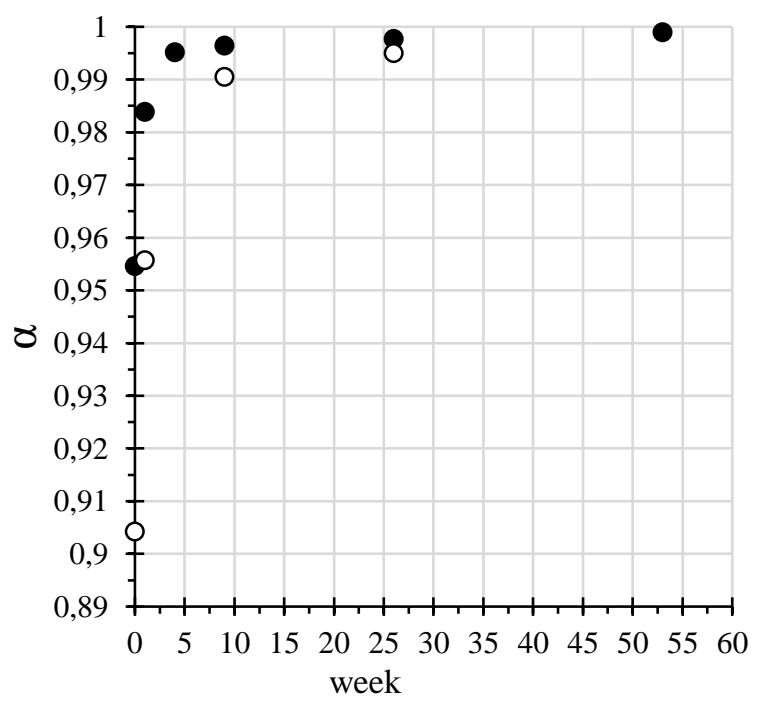

Figure 4: Rate of crosslinking reaction $(\alpha)$ of the composite $(\bullet)$ and the epoxy resin without fibres $(\circ)$, as a function of the ageing time. 
Figure 4 also shows that the progress rate of the crosslinking reaction is slightly greater for the composite than for the resin without fibres, under the same curing conditions. For non-aged materials, $\alpha$ is respectively 0.956 for the composite and 0.904 for the resin without fibres. Thus, either the Tg of the composite is slightly higher than the resin's one, or the fibres have an impact on crosslinking thereof.

To answer this question, the reversible signals obtained by the mDSC tests, i.e. Tg of the composite and resin without fibres, were analysed (Figure 5).

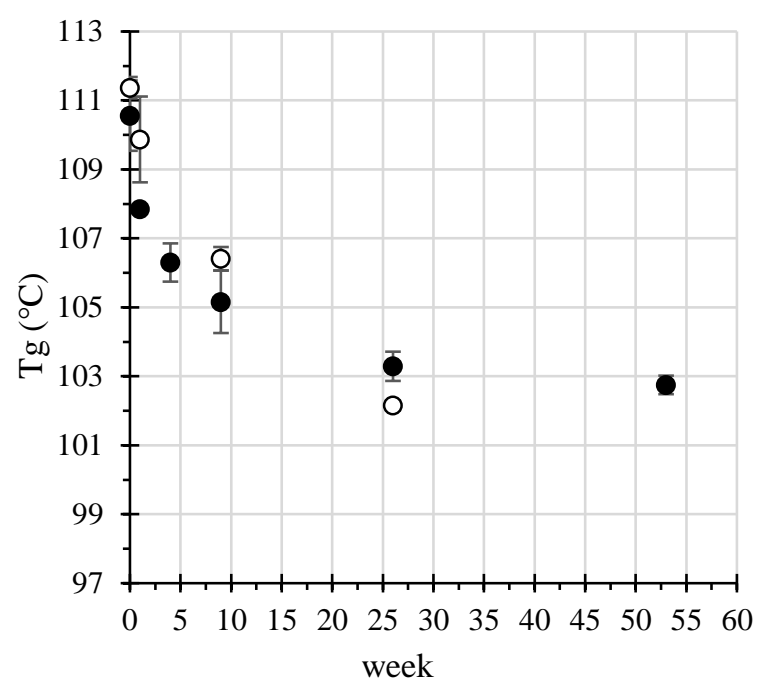

Figure 5: Evolution of the Tg measured by $\mathrm{mDSC}$ as a function of the ageing time for the composite $(\bullet)$ and the epoxy resin without fibres (०) (Error bars indicate standard deviation).

Figure 5 shows that before ageing, the $\mathrm{Tg}$ of the composite $\left(110.6 \pm 1.0^{\circ} \mathrm{C}\right)$ and epoxy resin without fibres $(111.4$ $\pm 0.3^{\circ} \mathrm{C}$ ) are very close. It therefore seems that the resin without fibres is not less crosslinked than the resin in the composite. The slight difference in residual crosslinking enthalpy can then be related to the presence of the fibres in the composite. The fibres could physically or chemically interact and limit the crosslinking, which would explain the lower crosslinking enthalpy measured for the composite. The composite $\Delta \mathrm{H}_{\mathrm{T}}$ would therefore probably be lower than the $\Delta \mathrm{H}_{\mathrm{T}}$ of the resin without fibres. The fibres would thus act as obstacles to the crosslinking of the matrix starting from a certain level of crosslinking of the polymer network.

Furthermore, the decrease in the crosslinking enthalpy (Figure 3) and the increase in $\alpha$ (Figure 4) mean that the crosslinking rate of the epoxy network increases during ageing cycles. This is explained by the exposure of the composite to a temperature of $55^{\circ} \mathrm{C}$, which may be characterized as "post-curing". This temperature allows the epoxy and amine groups, which could not react during the various stages of process, to react. As the increase in the crosslinking rate leads to a decrease in the mobility of the macromolecular chains of the polymer network, it 
is therefore usually accompanied by a shift in the glass transition temperature $(\mathrm{Tg})$ towards the high temperatures (Danieley and Long Jr., 1981). However, opposite to what is expected, the Tg of the materials decreases during the ageing cycles (Figure 5). Thus, the observed $\mathrm{Tg}$ evolutions result from other phenomena than the postcrosslinking mentioned previously.

The water in contact with the matrix during ageing can lead to chemical (non-reversible) and/or physical (plasticization) modifications, which would explain the decrease of Tg.

To identify the phenomena, related to water, that may be responsible for this evolution of the $\mathrm{Tg}$, the evolution of the $\mathrm{Tg}$ as a function of the water intake of the composite during ageing was studied. To do so, the composite samples were weighed after each ageing time. As illustrated in Figure 6, the evolution of the Tg as a function of the water intake is linear.

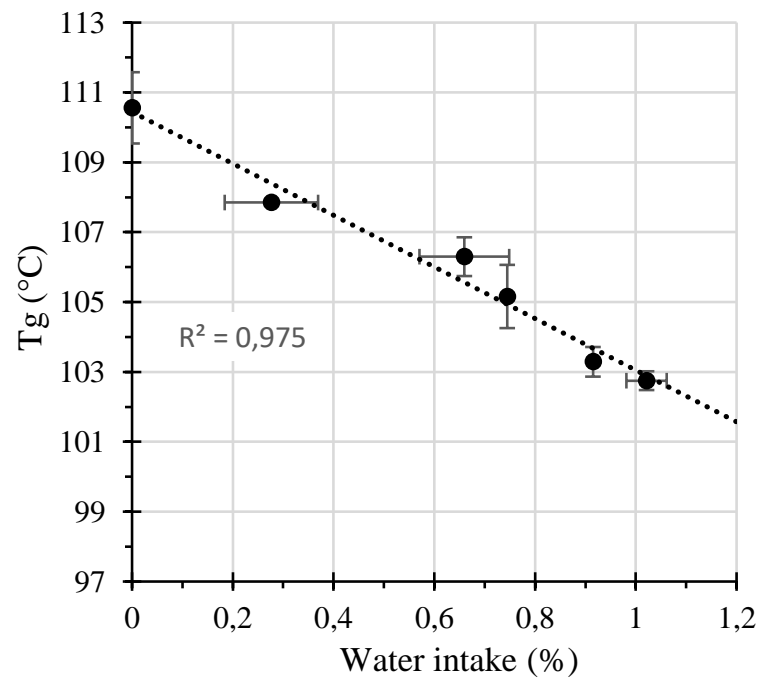

Figure 6: Evolution of the composite $\mathrm{Tg}$ as a function of water intake.

DVS analyses (Figure 7) have shown that the diffusion of water in flax fibres is faster than in the composite, which is itself faster than in the epoxy resin without fibres. Moreover, the final mass of the samples is greater than the initial mass for the composite and epoxy resin without fibres but not for the fibres alone. So, for the composite, we can assume that only the resin "stores" water molecules during ageing cycles, i.e. it is only the matrix which is responsible for the measured mass gain after hygrothermal ageing. 


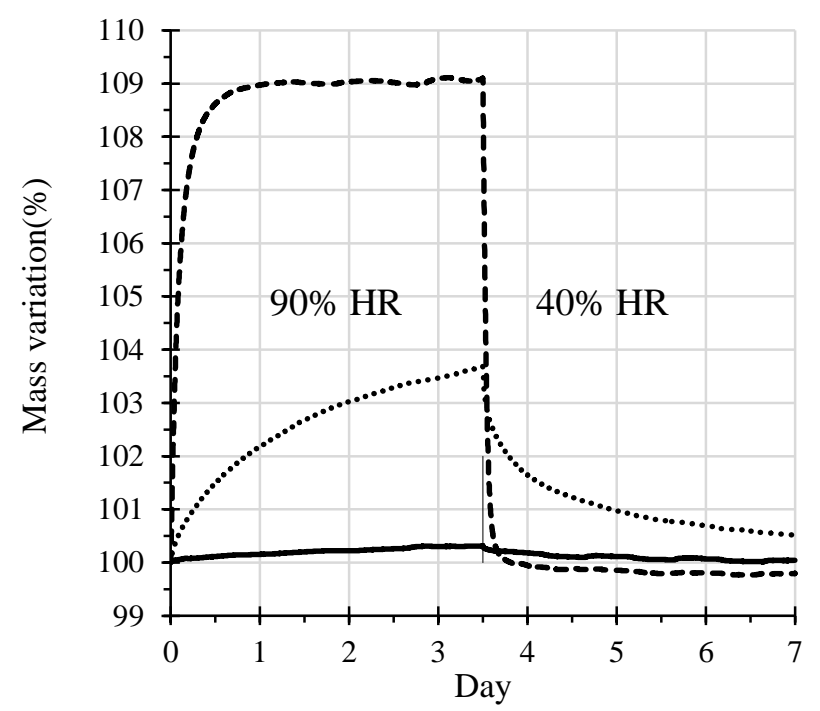

Figure 7: DVS measures on flax fibres (----), epoxy resin (一) and composite (.....)

To verify whether, in the composite, water is only stored in the resin, the empirical relationship of Gordon Taylor (Gordon and Taylor, 1952; Hodge et al., 1996) was used. Gordon and Taylor proposed an empirical relation to predict the evolution of a polymer $\mathrm{Tg}$ as a function of plasticization, according to the absorbed water:

$\frac{1}{T g}=\frac{f_{\text {water }}}{T g_{\text {water }}}+\frac{f_{\text {polymer }}}{T g_{\text {polymer, } d r y}}$

With: $f_{\text {water }}$ and $f_{\text {polymer }}$ respectively the mass fractions of water and of the polymer; $T g_{\text {water }}$ and $T g$ polymer $d r y$ respectively the Tg of water (134K) (Jenniskens and Blake, 1996; Sugisaki et al., 1968) and the Tg of the polymer in its dry initial state.

For this purpose, the mass fraction of water, calculated as a function of the mass gain of the composite, was reduced to the mass of resin using the mass proportion of resin in the composite, which is $47 \%$.

The calculated $\mathrm{Tg}$ results and the experimental measurements performed on the composite are presented as a function of the ageing time (Figure 8). These different data are superimposed; it therefore appears that the GordonTaylor relationship enables to predict the evolution of the $\mathrm{Tg}$ of the composite for the ageing times up to 1 year. Consequently, it seems that the decrease in $\mathrm{Tg}$ is mainly induced by a plasticization of the network, i.e. a rupture of the Van der Waals inter-chain forces and of the hydrogen bonds initially formed between the polymer chains, that increases the mobility of the macromolecular chains of the polymer. 


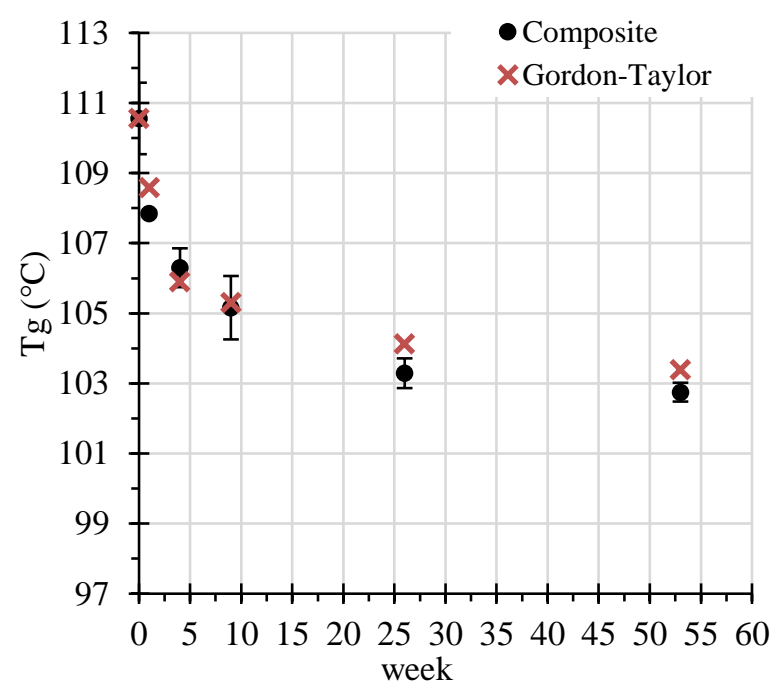

Figure 8: Evolution of the Tg composite and Gordon-Taylor relation as a function of the ageing time.

Finally, it therefore seems that the post-crosslinking of the resin in the composite has only a very negligible influence on the glass transition temperature, compared to the influence of the water intake.

\subsection{Physical evolutions of the resin as a function of ageing time}

In order to confirm that the decrease in Tg observed is mainly related to physical plasticization phenomena in the materials, samples of composite and resin without fibres, unaged and aged 9 and 26 weeks, were dried (Figure 9). The drying, 9-weeks long i.e. up to constant masses, was carried out in a desiccator containing silica gel at room temperature, to limit the influence of the temperature on a possible resin post-crosslinking.

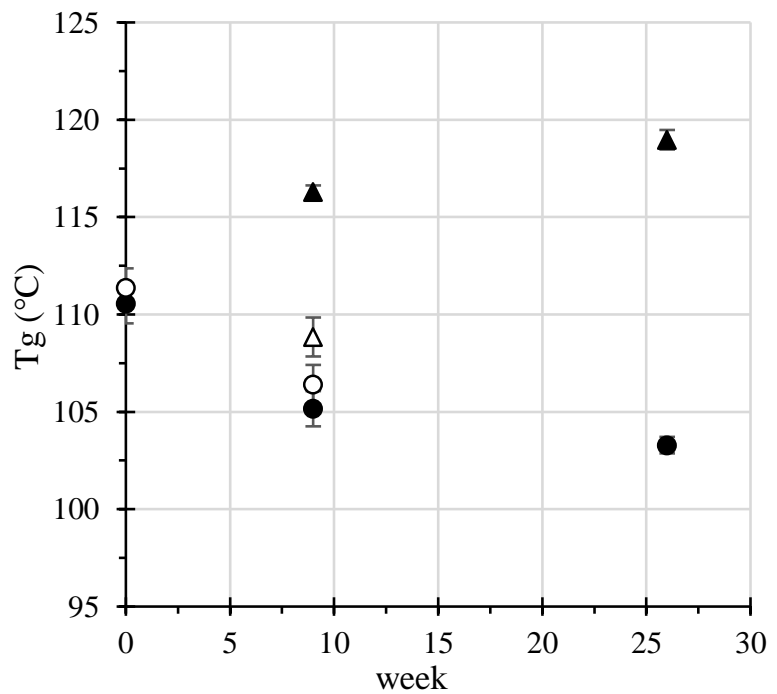


Figure 9: Evolution of the $\mathrm{Tg}$ as a function of the ageing time before drying for composite $(\bullet)$ and resin without fibres (०) and after 2 months of drying for the composite $(\boldsymbol{\Delta})$ and resin without fibres $(\Delta)$. (Error bars indicate standard deviation).

The results for the composite are showed in Figure 9. It appears that the drying induces an increase in the $\mathrm{Tg}$ compared to the initial $\mathrm{Tg}\left(110.6 \pm 1.0^{\circ} \mathrm{C}\right)$. This means that the shift of $\mathrm{Tg}$ towards the low temperatures caused by ageing is cancelled out once the water has been extracted and that the effect of post-crosslinking is then observable by increases in $\mathrm{Tg}$.

For the epoxy resin (Figure 9), the increase in Tg after 2 months of drying is lower than for the composite and the $\mathrm{Tg}$ remains lower than the initial $\mathrm{Tg}$. This can be explained by a quantity of residual water caused by a slower water extraction due to the absence of fibres: the fibres favour the diffusion and extraction of water out of the material.

Analyses of differential scanning calorimetry in modulated mode have therefore made it possible to note that the evolution of the resin $\mathrm{Tg}$ of the composite during ageing seems mainly linked to a matrix physical plasticization. To confirm these interpretations, Fourier transform infrared spectroscopy (IRTF) analyses were carried out on the composite and resin without fibres samples to ensure that the decrease in $\mathrm{Tg}$ during ageing is not also related to a chemical evolution of the resin.

\subsection{Chemical evolutions of the resin with the ageing time}

The infrared spectra of the resin without fibres obtained in attenuated total reflectance mode (ATR), before and after ageing, are presented in Figure 10. It appears that the peak present at $908 \mathrm{~cm}^{-1}$ decreases over the ageing cycles. This peak is attributed to the epoxy groups of the prepolymer (Corsetti et al., 2013; González et al., 2012). Its decrease, during ageing, indicates a better crosslinking of the network, which is in agreement with the decrease in enthalpy (Figure 3) and the increase in the degree of progress of the crosslinking reaction (Figure 4). In addition, by comparison of the IRTF spectrograms, no other evolution is observed whatever the ageing, up to 1 year of exposure. Thus, these ageing processes do not lead to significant surface chemical degradation of the resin. 

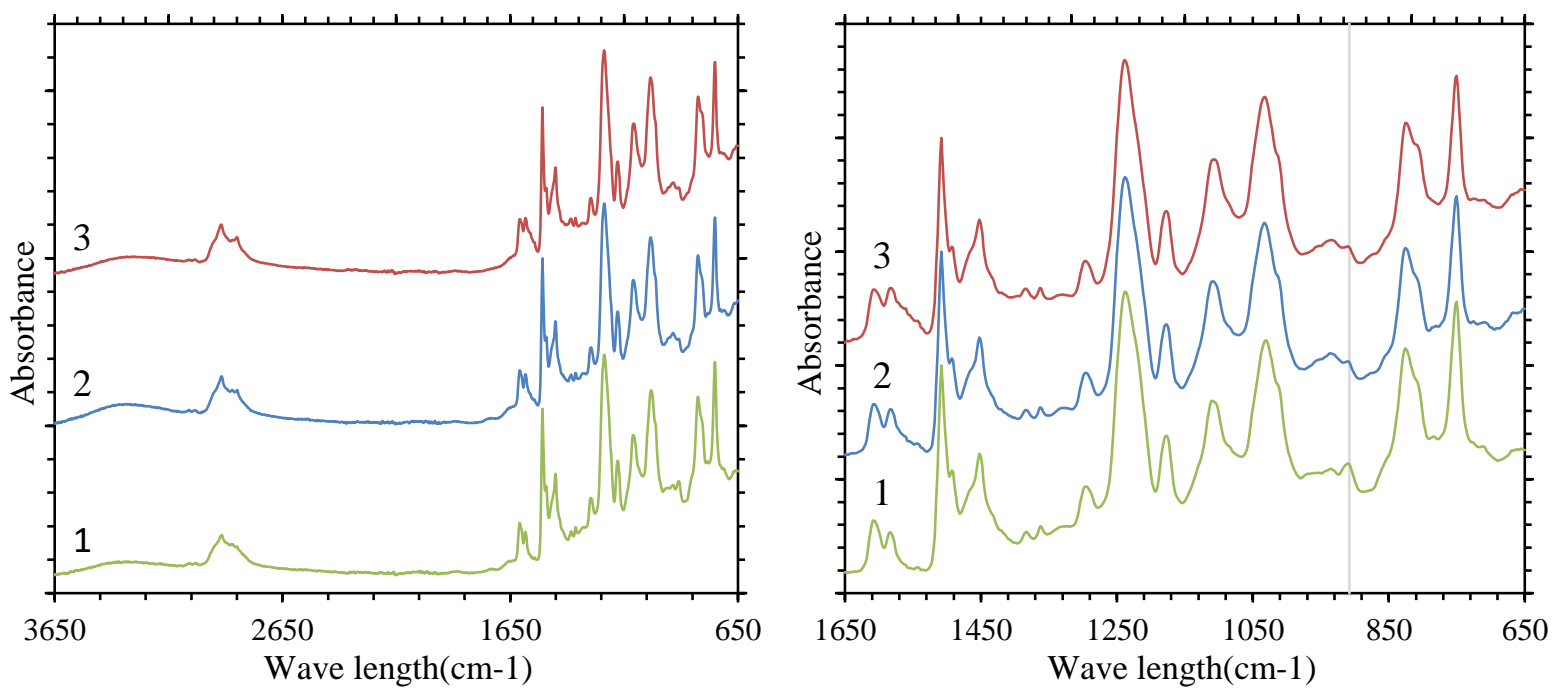

Figure 10: Infrared Spectra of the resin: 1) unaged, 2) aged 4 weeks and 3) aged 26 weeks.

IRTF spectrometer measurements were also carried out on the composite samples (Figure 11). Firstly, it appears that the spectra obtained for the composite samples are very close to those of the resin without fibres (Figure 10). This can be explained by the attenuated total reflectance mode (ATR) which enables to characterize only the surface of the samples. Since in the composite, the fibres are coated with matrix and since the characterized thickness is of the order of $10 \mu \mathrm{m}$, it is therefore the resin which is analysed. It appears that no significant chemical degradation was observed on the surface of the samples. Thus, the presence of flax fibres does not affect the chemical evolution of the polymer at the surface. IRTF analyses tend to confirm the physical origin, i.e. plasticization, of the decrease in Tg already demonstrated by mDSC.
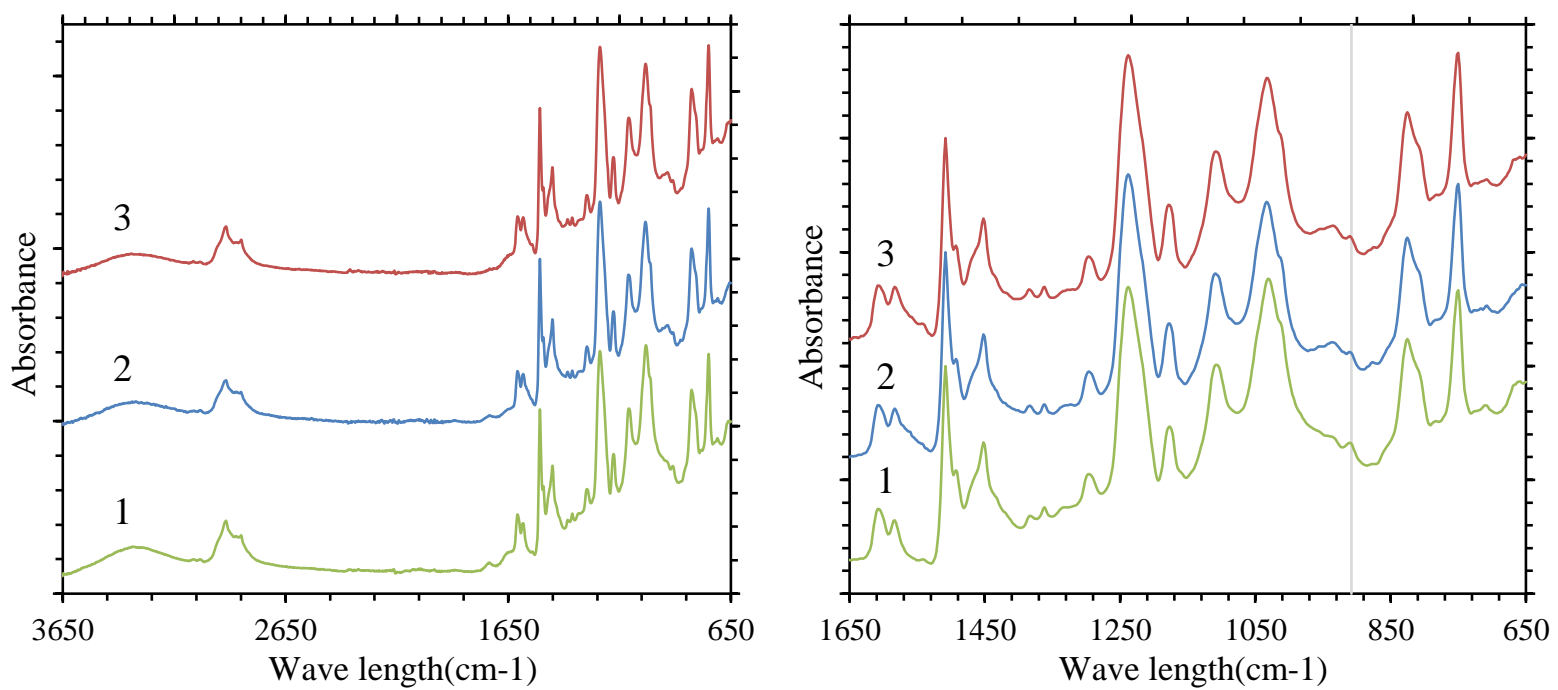

Figure 11: Infrared spectra of the composite: 1) unaged, 2) aged 4 weeks and 3) aged 52 weeks 
4. Identification of the phases responsible for the variation in the ultimate tensile strength of the composite.

The physicochemical analyses highlighted the phenomena of physical plasticization and post-crosslinking of the resin during ageing. To determine the influence of these phenomena on the mechanical properties of the epoxy matrix, tensile tests were carried out. Figure 12 shows the evolution of the ultimate tensile strength of the resin without fibres as a function of the degree of progress of the crosslinking reaction.

According to the standard deviations (Figure 12), it appears that $\sigma_{\max }$ is mainly governed by network postcrosslinking and is sparsely impacted by water intake. Thus, unlike the composite (Figure 2), the ultimate tensile strength measured on the epoxy resin without fibres samples does not drop during ageing. The phenomena of physical plasticization and post-crosslinking of the resin within the composite, highlighted by physicochemical analyses, do not therefore seem to be responsible of the drop in the composite ultimate tensile strength.

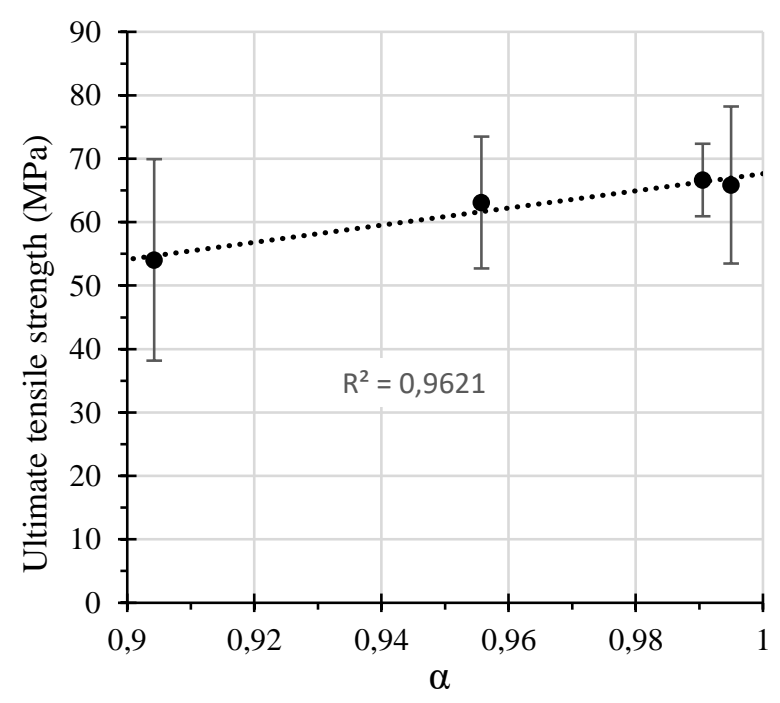

Figure 12: Evolution of the ultimate tensile strength of the epoxy resin without fibres as a function of crosslinking reaction rate (Error bars indicate standard deviation).

In addition, the tensile tests carried out on flax fibre bundles (Figure 13) indicate that the mechanical properties of the uncoated fibres are not damaged before 9 weeks of ageing. Therefore, the fibres do not seem to be directly responsible for this change of the composite propriety. 


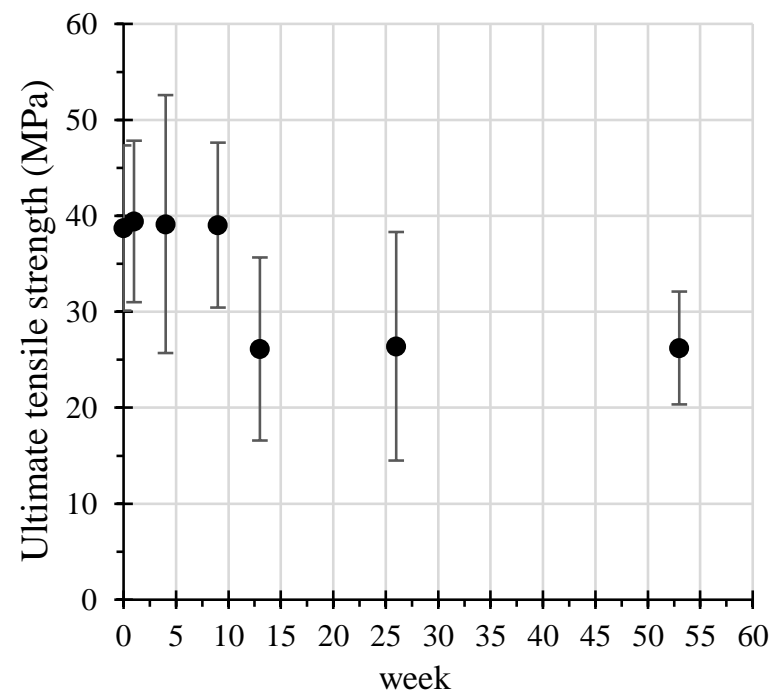

Figure 13: Evolution of the ultimate tensile strength of fibres bundle as a function of the ageing time. (Error bars indicate standard deviation).

In view of the results of the physicochemical and mechanical tests, the drop in the ultimate tensile strength of the composite observed after the first week of ageing is therefore not induced by changes in the resin or the fibres. It therefore seems that this drop is related to the interfaces within the material. In order to confirm this assumption, observations with a scanning electron microscope (SEM) were carried out on transverse sections of the composite specimens.

Figure 14 presents the observations of composite cross sections $\left(90^{\circ}\right)$ made on the unaged material, after 1 week and 1 year of ageing. On the unaged material (Figure 14-a), an imperfect fibre/matrix cohesion was observed in some very localized areas that exhibited residues of the cortex of the flax stem. This phenomenon was also highlighted for the $0^{\circ}$ test samples (Cadu et al., 2019).
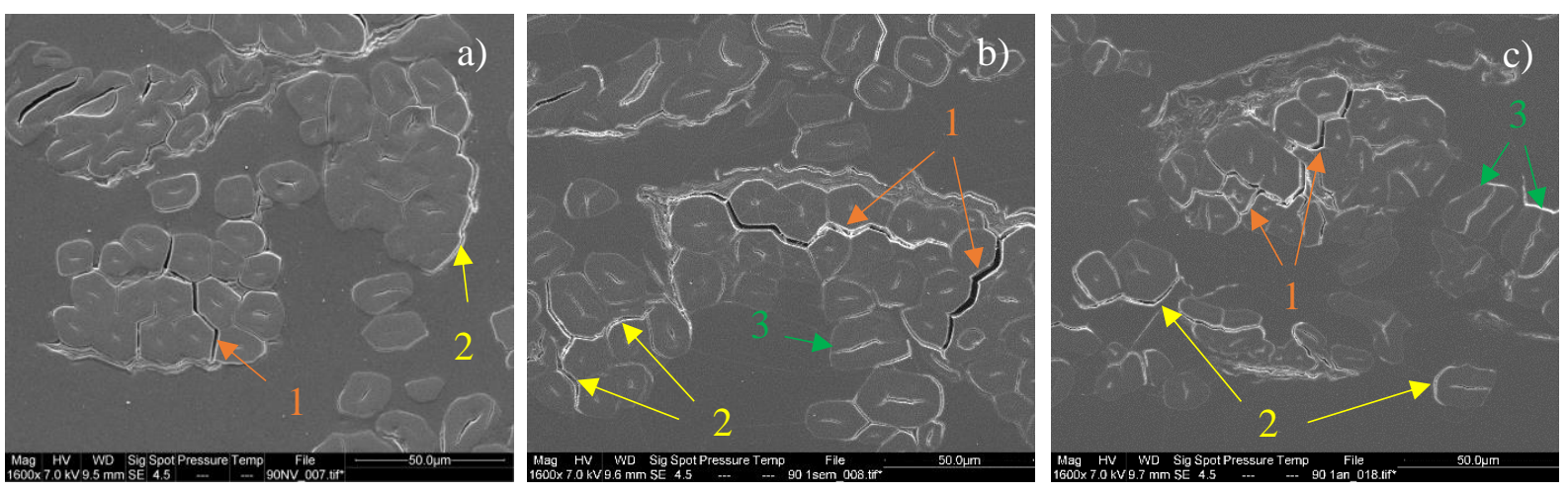

Figure 14: SEM observations of $90^{\circ}$ composite sections a) unaged, after b) 1 week and c) 52 weeks of ageing. The arrows indicate 1) fibre/fibre debonding inside the fibres bundles, 2) fibres/matrix debonding and 3) cracked fibres. 
After 1 week of ageing (Figure 14-b), fibre/fibre and fibre/matrix debondings appear larger and more numerous than for the unaged material. In addition, cracks initiated at the lumen level appear in some of the fibres. This creation of additional flaws facilitates the initiation of cracks when the material is subjected to tensile forces. As the shear strengths of the interface between two elementary fibres and of the interface between epoxy resin and flax fibres are respectively about 2.9 MPa (Beakou and Charlet, 2013) and 22.5 MPa (Antoine Le Duigou et al., 2014), these debondings may explain the drop in the ultimate tensile strength in the composite, observed after the first week of ageing thanks to the mechanical tests (Figure 2). Debonding can be due to the differential swelling between the fibres and the matrix during hygrothermal ageing cycles (Cadu et al., 2019; Li and Xue, 2016) and the degradation of the covalent bonds created between the epoxy and amine functions of the resin and the hydroxyl functions of the fibres (Antoine Le Duigou et al., 2014). The decrease in the ultimate tensile strength of the composite observed between the first and the ninth week indicates that the debonding phenomenon must be accentuated during these ageing cycles. Finally, after 52 weeks of exposure (Figure 14-c), the cracks initiated at the lumen level in some fibres have spread transversely to their surface.

Therefore, the combination of the physicochemical analyses on the composite and the resin without fibres, the mechanical tests on the constituents and the SEM observations, carried out on the composite sections, indicate that the drop in the ultimate tensile strength of the composite observed during the first ageing cycles (Figure 2) is mainly induced by morphological changes within the composite and in particular the degradation of the fibre/fibre and fibre/matrix interfaces.

\section{Relation between modulus and physicochemical properties}

In order to determine the origin of the evolution of the composite transverse modulus observed by the tensile tests (Figure 2) the transverse modulus as a function of the water mass content and the $\mathrm{Tg}$ of the composite is presented in figure 15. It appears that the evolution of the composite transverse modulus is proportional to the evolution of the glass transition temperature; it results in a linear relationship (Figure 15). Moreover, the evolution of the composite modulus as a function of the quantity of water is also linear, as shown in Figure 15. 


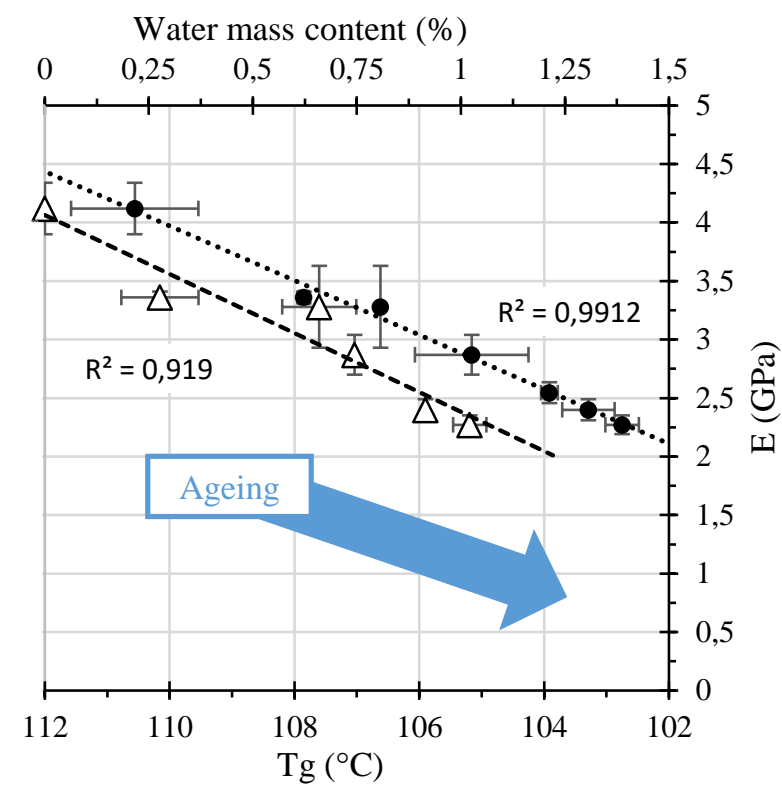

Figure 15: Evolution of the Young modulus as a function of the $\mathrm{Tg}$ of the composite $(\bullet)$ and of its water content $(\Delta)$. (Error bars indicate standard deviation).

The transversal Young modulus of the composite is therefore mainly governed by the matrix and its evolution during hygrothermal ageing cycles is directly and linearly proportional to the $\mathrm{Tg}$ of the material. It therefore appears that the modulus reduction is related to the evolution of the physicochemical properties of the resin during these ageing cycles and more particularly to the physical plasticization of the epoxy network induced by the water molecules.

Furthermore, damages induced to the interfaces after the $1^{\text {st }}$ week (Figure 14-b) have an important effect on the tensile strength (Figure 2) but do not seem to amplify the physical plasticization of the matrix within the composite, even if the fibre/fibre and fibre/matrix debonding facilitates the diffusion of water in the material. This can be explained by the fact that the water diffusion is already faster in the fibres than in the matrix. Thus, from the start, the resin is in contact with more water molecules than it can absorb, and the increase in diffusivity in the composite does not therefore affect the water intake of the resin within the composite.

Figure 16 provides a scenario for the mechanisms involved in the $90^{\circ}$ test samples of the unidirectional flax/epoxy composite during cyclic hygrothermal ageing, up to 1 year. The number of icons schematically represents the quantity of elements present in the material and its evolution is only provided as a trend to highlight the qualitative changes that take place in the composite during ageing. 


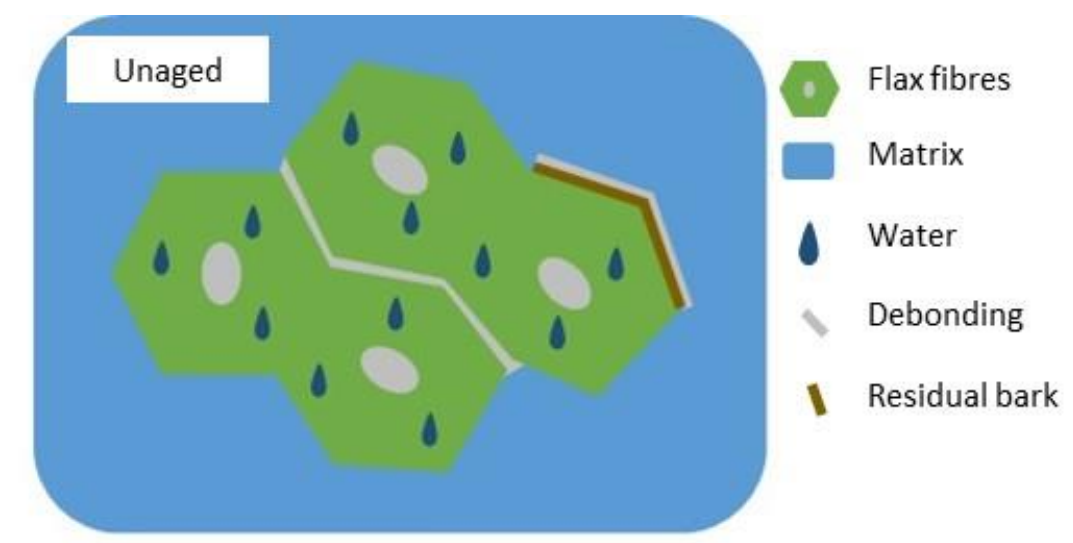

(a) Imperfect fiber / matrix adhesion in some areas and some fiber / fiber debonding within the bundles (SEM)

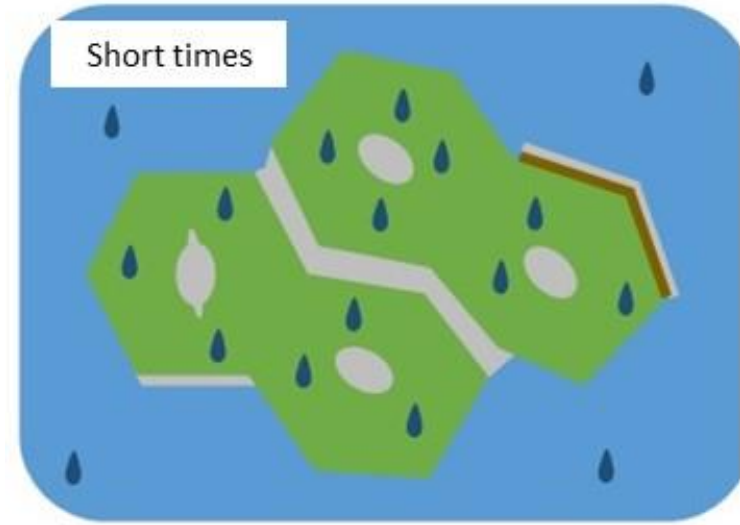

(b) Interfaces damage cracks initiation (SEM) which cause a drop in $\sigma_{\max }$. Water storage in the matrix (DVS) which induces a matrix physical plasticization (mDSC) and a drop in composite Modulus $\mathrm{E}$

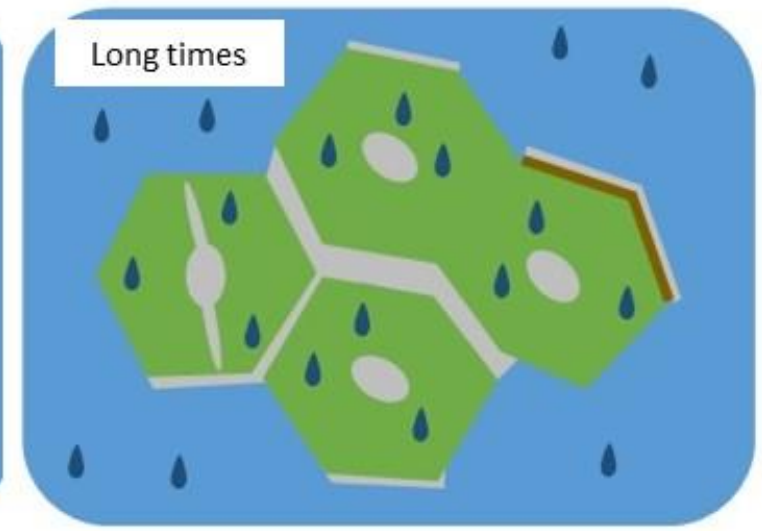

(c) More severe interfaces damage and complete cracking of some fibers (SEM). Greater water storage in the matrix (DVS) which increases the matrix physical plasticization (mDSC) responsible for the drop in composite Modulus E

Figure 16: Influence of cyclic hygrothermal ageing on the unidirectional flax/epoxy composite $\left(90^{\circ}\right)$.

\section{Conclusion}

In this study, the influence of a cyclic hygrothermal ageing on the transverse properties of a flax/epoxy composite has been studied. The tensile tests carried out on the unidirectional samples $\left(90^{\circ}\right)$ revealed a drop in the ultimate transverse strength, from the first week of ageing, and a smaller decrease until the ninth week of ageing. Then, between 9 and 52 weeks, the tensile strength seems to stabilize. As for the Young modulus, it decreases according to a hyperbolic profile during the cycles, for the durations of ageing test periods (up to 1 year).

Multiscale analyses performed on materials allowed to identify the mechanisms responsible of these changes in the mechanical properties. Thus, mass monitoring of the specimens showed a water uptake within the composite over the ageing cycles, that would mainly be stored in the matrix, as pointed out by the empirical relationship of 
Gordon Taylor. The decrease of the composite resin glass transition temperature during cyclic hygrothermal ageing would therefore be related to a physical plasticization phenomenon of the polymer network.

The tensile tests carried out on the epoxy resin without fibres have shown that the ultimate tensile strength of the matrix is mainly governed by the post-crosslinking and is not much affected by the physical plasticization related to the water absorption. In addition, the mechanical tests carried out on the fibre bundles did not explain the transverse ultimate tensile strength drop of the composite after the first week of ageing. This drop in tensile strength is therefore related to the creation of flaws in the material and more particularly to fibre/fibre and fibre/matrix debondings, as observed by Scanning Electron Microscope. These pictures also highlighted the creation and then the propagation of cracks initiated in the lumen of some fibres.

Finally, this study demonstrated that the evolution of the transverse Young modulus of the composite during hygrothermal ageing is mainly governed by the resin and would mainly depend on the physical plasticization state of the latter.

\section{Acknowledgement}

This project is supported by the Bourgogne Franche-Comté region -FRANCE (2015-9201 AAO 04850 3040).

\section{References}

Amiri, A., Triplett, Z., Moreira, A., Brezinka, N., Alcock, M., Ulven, C.A., 2017. Standard density measurement method development for flax fiber. Ind. Crops Prod. 96, 196-202. https://doi.org/https://doi.org/10.1016/j.indcrop.2016.11.060

Assarar, M., Scida, D., El Mahi, A., Poilâne, C., Ayad, R., 2011. Influence of water ageing on mechanical properties and damage events of two reinforced composite materials: Flax-fibres and glass-fibres. Mater. Des. 32, 788-795. https://doi.org/10.1016/j.matdes.2010.07.024

Azwa, Z.N., Yousif, B.F., Manalo, A.C., Karunasena, W., 2013. A review on the degradability of polymeric composites based on natural fibres. Mater. Des. 47, 424-442. https://doi.org/https://doi.org/10.1016/j.matdes.2012.11.025

Baley, C., 2002. Analysis of the flax fibres tensile behaviour and analysis of the tensile stiffness increase. Compos. Part A Appl. Sci. Manuf. 33, 939-948. https://doi.org/https://doi.org/10.1016/S1359-835X(02)00040-4

Baley, C., Le Duigou, A., Bourmaud, A., Davies, P., 2012. Influence of drying on the mechanical behaviour of flax fibres and their unidirectional composites. Compos. Part A Appl. Sci. Manuf. 43, 1226-1233. 
https://doi.org/10.1016/j.compositesa.2012.03.005

Beakou, A., Charlet, K., 2013. Mechanical properties of interfaces within a flax bundle-Part II: Numerical analysis. Int. J. Adhes. Adhes. 43, 54-59. https://doi.org/https://doi.org/10.1016/j.ijadhadh.2013.01.013

Berges, M., Léger, R., Placet, V., Person, V., Corn, S., Gabrion, X., Rousseau, J., Ramasso, E., Ienny, P., Fontaine, S., 2016. Influence of moisture uptake on the static, cyclic and dynamic behaviour of unidirectional flax fibre-reinforced epoxy laminates. Compos. Part A Appl. Sci. Manuf. 88, 165-177. https://doi.org/https://doi.org/10.1016/j.compositesa.2016.05.029

Cadu, T., Berges, M., Sicot, O., Person, V., Piezel, B., Van Schoors, L., Placet, V., Corn, S., Léger, R., Divet, L., Ienny, P., Fontaine, S., 2018. What are the key parameters to produce a high-grade bio-based composite? Application to flax/epoxy UD laminates produced by thermocompression. Compos. Part B Eng. 150. https://doi.org/10.1016/j.compositesb.2018.04.059

Cadu, T., Van Schoors, L., Sicot, O., Moscardelli, S., Divet, L., Fontaine, S., 2019. Cyclic hygrothermal ageing of flax fibers' bundles and unidirectional flax/epoxy composite. Are bio-based reinforced composites so sensitive? Ind. Crops Prod. 141. https://doi.org/10.1016/j.indcrop.2019.111730

Chilali, A., Assarar, M., Zouari, W., Kebir, H., Ayad, R., 2018. Analysis of the hydro-mechanical behaviour of flax fibre-reinforced composites: Assessment of hygroscopic expansion and its impact on internal stress. Compos. Struct. 206, 177-184. https://doi.org/https://doi.org/10.1016/j.compstruct.2018.08.037

Corsetti, R.R., Neumeyer, T., May, M., Jandrey, D., Altstaedt, V., Cardozo, N.S.M., 2013. Modeling and estimation of parameters for the curing of an epoxy/amine system. Polym. Test. 32, 647-654. https://doi.org/https://doi.org/10.1016/j.polymertesting.2013.03.011

Danieley, N.D., Long Jr., E.R., 1981. Effects of curing on the glass transition temperature and moisture absorption of a neat epoxy resin. J. Polym. Sci. Polym. Chem. Ed. 19, 2443-2449. https://doi.org/10.1002/pol.1981.170191007

Dhakal, H., Zhang, Z., Richardson, M., 2007. Effect of water absorption on the mechanical properties of hemp fibre reinforced unsaturated polyester composites. Compos. Sci. Technol. 67, 1674-1683. https://doi.org/10.1016/j.compscitech.2006.06.019

El Yagoubi, J., Lubineau, G., Saghir, S., Verdu, J., Askari, A., 2014. Thermomechanical and hygroelastic properties of an epoxy system under humid and cold-warm cycling conditions. Polym. Degrad. Stab. 99, 146-155. https://doi.org/https://doi.org/10.1016/j.polymdegradstab.2013.11.011

González, M.G., Cabanelas, J.C., Baselga, J., 2012. Applications of FTIR on Epoxy Resins - Identification, 
Monitoring the Curing Process, Phase Separation and Water Uptake, in: Infrared Spectroscopy - Materials Science, Engineering and Technology. https://doi.org/10.5772/36323

Gordon, M., Taylor, J.S., 1952. Ideal copolymers and the second-order transitions of synthetic rubbers. i. noncrystalline copolymers. J. Appl. Chem. 2, 493-500. https://doi.org/10.1002/jctb.5010020901

Gradeci, K., Labonnote, N., Time, B., Köhler, J., 2017. Mould growth criteria and design avoidance approaches in wood-based materials - A systematic review. Constr. Build. Mater. 150, 77-88. https://doi.org/https://doi.org/10.1016/j.conbuildmat.2017.05.204

Hodge, R.M., Bastow, T.J., Edward, G.H., Simon, G.P., Hill, A.J., 1996. Free Volume and the Mechanism of Plasticization in Water-Swollen Poly(vinyl alcohol). Macromolecules 29, 8137-8143. https://doi.org/10.1021/ma951073j

ISO527-2, 2012. Plastics — Determination of tensile properties — Part 2: Test conditions for moulding and extrusion plastics.

Jenniskens, P., Blake, D.F., 1996. Crystallization of Amorphous Water Ice in the Solar System. Astrophys. J. 473, 1104-1113. https://doi.org/10.1086/178220

Jeyapragash, R., Srinivasan, V., Sathiyamurthy, S., 2020. Mechanical properties of natural fiber/particulate reinforced epoxy composites - A review of the literature. Mater. Today Proc. 22, 1223-1227. https://doi.org/https://doi.org/10.1016/j.matpr.2019.12.146

Kim, H.J., Seo, D.W., 2006. Effect of water absorption fatigue on mechanical properties of sisal textile-reinforced composites. Int. J. Fatigue 28, 1307-1314. https://doi.org/https://doi.org/10.1016/j.ijfatigue.2006.02.018

Koolen, G., Soete, J., van Vuure, A.W., 2020. Interface modification and the influence on damage development of flax fibre - Epoxy composites when subjected to hygroscopic cycling. Mater. Today Proc. https://doi.org/https://doi.org/10.1016/j.matpr.2020.01.183

Le Duigou, A., Baley, C., 2014. Coupled micromechanical analysis and life cycle assessment as an integrated tool for natural fibre composites development. J. Clean. Prod. 83, 61-69. https://doi.org/https://doi.org/10.1016/j.jclepro.2014.07.027

Le Duigou, A., Bourmaud, A., Baley, C., 2015. In-situ evaluation of flax fibre degradation during water ageing. Ind. Crops Prod. 70, 204-210. https://doi.org/https://doi.org/10.1016/j.indcrop.2015.03.049

Le Duigou, A, Bourmaud, A., Davies, P., Baley, C., 2014. Long term immersion in natural seawater of Flax/PLA biocomposite. Ocean Eng. 90, 140-148. https://doi.org/https://doi.org/10.1016/j.oceaneng.2014.07.021

Le Duigou, Antoine, Kervoelen, A., Le Grand, A., Nardin, M., Baley, C., 2014. Interfacial properties of flax fibre- 
epoxy resin systems: Existence of a complex interphase. Compos. Sci. Technol. 100, 152-157. https://doi.org/https://doi.org/10.1016/j.compscitech.2014.06.009

Li, Y., Xue, B., 2016. Hydrothermal ageing mechanisms of unidirectional flax fabric reinforced epoxy composites. Polym. Degrad. Stab. 126, 144-158. https://doi.org/https://doi.org/10.1016/j.polymdegradstab.2016.02.004 Mendes, S., Hugen, L.N., DOS Santos, R.D., Toledo Filho, R.D., Ferreira, S.R., 2019. Influence of Water Amount and Immersion Time on the Sisal Fibers Hornification Process. J. Nat. Fibers 00, 1-10. https://doi.org/10.1080/15440478.2019.1697990

Newman, R.H., 2009. Auto-accelerative water damage in an epoxy composite reinforced with plain-weave flax fabric. Compos. Part A Appl. Sci. Manuf. 40, 1615-1620. https://doi.org/https://doi.org/10.1016/j.compositesa.2009.07.010

Poilâne, C., Cherif, Z.E., Richard, F., Vivet, A., Ben Doudou, B., Chen, J., 2014. Polymer reinforced by flax fibres as a viscoelastoplastic material. Compos. Struct. 112, 100-112. https://doi.org/https://doi.org/10.1016/j.compstruct.2014.01.043

Prime, R.B., 1973. Differential scanning calorimetry of the epoxy cure reaction. Polym. Eng. Sci. 13, 365-371. https://doi.org/10.1002/pen.760130508

Roudier, A., 2012. Analyse multi-échelle du comportement hygro-mécanique des fibres de lin. Université Blaise Pascal - Clermont-Ferrand II. https://doi.org/tel-00741951

Scida, D., Assarar, M., Poilâne, C., Ayad, R., 2013. Influence of hygrothermal ageing on the damage mechanisms of flax-fibre reinforced epoxy composite. Compos. Part B Eng. 48, 51-58. https://doi.org/https://doi.org/10.1016/j.compositesb.2012.12.010

Sodoke, F.K., Toubal, L., Laperrière, L., 2019. Wetting/drying cyclic effects on mechanical and physicochemical properties of quasi-isotopic flax/epoxy composites. Polym. Degrad. Stab. 161, 121-130. https://doi.org/10.1016/j.polymdegradstab.2019.01.014

Sodoke, F.K., Toubal, L., Laperrière, L., 2016. Hygrothermal effects on fatigue behavior of quasi-isotropic flax/epoxy composites using principal component analysis. J. Mater. Sci. 51, 10793-10805. https://doi.org/10.1007/s10853-016-0291-z

Sugisaki, M., Suga, H., Seki, S., 1968. Calorimetric Study of the Glassy State. IV. Heat Capacities of Glassy Water and Cubic Ice. Bull. Chem. Soc. Jpn. 41, 2591-2599. https://doi.org/10.1246/bcsj.41.2591

Yan, L., Chouw, N., 2015. Effect of water, seawater and alkaline solution ageing on mechanical properties of flax fabric/epoxy composites used for civil engineering applications. Constr. Build. Mater. 99, 118-127. 
https://doi.org/10.1016/j.conbuildmat.2015.09.025 
